\title{
PERCEPÇÃO DA CONDIÇÃO DE SAÚDE ENTRE MULHERES*
}

\author{
Marlí V. Mamede** \\ Juliana V. Bueno*** \\ Sônia M. V. Bueno***
}

\begin{abstract}
RESUMO: Trata-se de uma pesquisa qualitativa, que objetivou verificar como um grupo de mulheres de baixa renda identificava sua condição de saúde. Foram entrevistadas $\mathbf{4 2}$ mulheres individualmente e a análise feita através do conteúdo de suas falas. Foi possível identificar que o conceito de saúde para esse grupo de mulheres está ligado à atividade física, ao sentido da vida, como também à ausência de doença. A tristeza, dor, desânimo, desconforto e medo de dependência foram os principais motivos alegados pelas mulheres que se percebiam como doentes. Discute-se a importância destes achados na prestação de assistência orientada para a saúde.
\end{abstract}

\begin{abstract}
This is a qualitative research that intends to verify how a group of poor women identify their health condition. Women were interviewed individually and the analysis was made according to their speeches. It was possible to identify that their concept of health was linked to physical activity, sensorial life and absence of diseases. The main reasons expressed by the women that perceived themselves as sick were sadness, pain, discouragement, discomfort and fear of dependence. The importance of these findings in the health-oriented care of women is here discussed.
\end{abstract}

\section{INTRODUÇÃO}

Antes que qualquer questão possa ser apropriadamente direcionada à sociedade, ela deve ser reconhecida como um elemento que necessita de ampla atenção, pois resolver problemas começa com a identificação dos mesmos.

Esta discussão cabe à Saúde da Mulher, visto que o termo saúde da mulher, recentemente tem significado mais do que o estudo da capacidade reprodutiva da mulher. Ao longo da história, em muitas sociedades, as mulheres foram valorizadas pela sua capacidade de perpetuar a espécie, o que como conseqüência, tem ajudado a explicar o mito de que todos os problemas de mulher podem ser reduzidos ao útero e às variações hormonais. ${ }^{(8)}$

Quando a OMS retoma a definição de saúde, reforçando que saúde é muito mais do que a ausência de doença, e incorpora aspectos sociais, culturais e emocionais, torna claro que a saúde da mulher deve ser enfatizada além do diagnóstico e tratamento de doenças. Deve ser analisada dentro do contexto do mundo em que vivemos ${ }^{(5)}$.

Dentro desta nova perspectiva, saúde não pode ser imposta e sim conquistada. Para tanto, para o alcance de saúde, faz-se necessário haver um comprometimento tanto por parte das pessoas, quanto dos profissionais e do governo. Desta maneira maneira, toma-se evidente que a Educação em Saúde é um fator essencial para o desenvolvimento deste compromisso(6).

Um ponto de partida para o trabalho que objetiva a promoção da saúde da mulher, neste contexto, é a busca do significado de saúde, que elas próprias têm de si mesmas. Repensando a questão, $\operatorname{BORGES}^{(1)}$, lembra que é condição no mundo humano, que os acontecimentos vividos só são significativos quando ganham possibilidades de serem nomeados, isto é, postos em linguagem.

\footnotetext{
* Trabalho apresentado no $44^{\circ}$ Congresso Brasileiro de Enf ermagem, Brasilia, D.F. 1992

** Docente do Departamento Materno Infantil da Escola de Enfermagem de Ribeirão Preto - U.S.P

*** Docente do Dept ${ }^{\circ}$ de Enfermagem Psiquiátrica e Ciências Humanas da Escola de Enf ermagem de Ribeirão Preto - U.S.P
} 
Partindo-se pois, deste referencial, e sentindo-se a necessidade de ouvir as próprias mulheres sobre 0 significado ou entendimento que elas próprias têm sobre o "estar doente" ou "saudável", é que se realizou este trabalho. Portanto, ao focalizar o conceito de saúde, buscando uma compreensão do senso comum, que as mulheres utilizam para a auto-identificação, expressando se estão doentes ou não, está se buscando uma aproximação às suas experiências de vida, e portanto, dando oportunidade para repensar a situação de vida das mulheres e os programas de saúde a elas direcionados.

Estes programas de educação para a saúde da mulher têm papel relevante na promoção da saúde, tanto a nível individual quanto coletivo. Para que estes sejam efetivos, deve-se criar oportunidades de levantamento de necessidades, executar ações educativas frente a esses problemas, bem como avaliar todo o processo, visando, fundamentalmente, a sensibilização, a conscientização e a responsabilidade da população alvo trabalhada, frente às questões.

Pompidou in BUENO e CHIEREGATO ${ }^{(3)}$, afirma que educação para a saúde é uma função inerente aos profissionais de saúde, e embora aparentemente simples e fácil, é um processo que requer numerosas especificidades do educador, para que as metas se tornem factíveis e atinjam os objetivos esperados. Não basta simplesmente of erecer informações, pois estar informado não significa, necessariamente, conhecer. Estar ciente não significa necessariamente fazer. Portanto, é necessário desenvolver o senso de responsabilidade individual e grupal, uma vez que é esse senso que pode conduzir às mais efetivas $e$ aceitas mudanças de comportamento.

E hoje, mais do que nunca, quando a mulher vem lutando e assumindo novos espaços, redescobrindo seu corpo, sua vida, o seu trabalho, enfim, o seu próprio existir, a educação tem tido peso considerável na Saúde da Mulher, contribuindo fortemente para a sua ascensão, para a luta contra a discriminação e o preconceito, que ao longo da história da civilização humana existiu em relação ao ser mulher. Desta maneira, as possibilidades de orientação e informação, nutriram e continuarão nutrindo o direito da expansão da mulher na sociedade, seja individualmente ou em grupo. Desta forma, sensibilizadas com estas questões, propôs-se realizar este estudo, com os objetivos de verificar como um grupo de mulheres define e identifica sua condição de saúde.

\section{METODOLOGIA}

Este estudo é parte do Projeto de Pesquisa Transcultural na área Saúde da Mulher, do Departamento de Enfermagem Materno-Infantil e Saúde Pública da Escola de Enf ermagem de Ribeirão Preto - Universidade de São Paulo, o qual busca apreender como as mulheres respondem e percebem os eventos vivenciados por elas e que dizem respeito à sua saúde e ao seu ser mulher.

Para este estudo, as experiências das mulheres são o principal objeto de investigação, visto que as suas percepções têm importância para a identificação de suas reais necessidades de saúde.

Portanto, esta é uma pesquisa qualitativa, cuja análise de conteúdo dos registros das falas de um grupo de mulheres de baixa renda, residentes em três bairros da periferia de Ribeirão Preto, foi empregada para a análise dos dados.

A coleta de dados foi realizada através de entrevistas individuais, face a face, onde se procurava respostas às seguintes questões:

1 - Saúde e doença têm o mesmo significado para as mulheres? O que significa cada um destes conceitos?

2 - Como as mulheres identificam sua situação se saúde, naquele momento, ou seja, se doente ou sadia?

Os registros das falas das mulheres foram escritos durante a entrevista, os quais serviram de subsídios para a identificação de temas ou categorias relacionados ao conceito de saúde entre as mulheres.

\section{ANÁLISE E DISCUSSÃO DOS DADOS}

A amostra constou de 42 mulhcres, oriundas de famílias carentes, cuja idade variou de 17 a 57 anos, sendo que a moda foi de 36 anos (14,2\%). Todas eram mães, sendo que $76,1 \%$ delas tiveram de 2 a 5 filhos. Quanto ao estado civil 47,6\% (20) eram casadas, $16,7 \%$ (7) solteiras, $16,7 \%$ (7) a masiadas, $11,9 \%(5)$ separadas ou desquitadas e $7,1 \%$ (3) viúvas. No que se refere ao tipo de trabalho realizado, quase a totalidade delas $(89,9 \%)$, desenvolvia trabalho doméstico, remunerado ou não, sendo que $50 \%$ (21) das mulheres entrevistadas, trabalhavam apenas no lar.

Portanto, pensar a saúde, especialmente a saúde da mulher, pressupõe situar as mudanças, nas relações em todos os planos da vida social - nas relações familiares, na imagem feminina, nas relações do co- 
tidiano,. Isto significa considerar a emancipação total da mulher, sua plena realização enquanto pessoa, através da atuação no mundo, contra os preconceitos que dificultam o seu desenvolvimento. ${ }^{(2)}$

Após o exame repetido das falas das mulheres entrevistadas (Anexo 1), foi possível identificar temas que despertam para a compreensão, por parte dessa clientela, de um conceito de saúde, o qual se mostrou abrangente e não meramente ligado à ausência de doença, muito presente no paradigma médico vigente.

As categorias representativas do conceito de saúde, de acordo com as falas das mulheres entrevistadas, podem ser assim sumariadas:

- saúde sendo ligada à atividade física

- saúde como dando sentido à vida

- saúde como sendo ausência de doença

Um dos fatores muito evidente nas falas das mulheres em estudo, que condiciona a percepção de sua saúde, é a posição no desempenho de seus papéis sociais, ou seja, sua participação no processo de produção. Isto pode ser evidenciado quando as mulheres denfiniam saúde como estando ligada à possibilidade de realização de atividades físicas. A fala das seguintes mulheres exemplifica tal categoria: saúde é ter coragem de fazer tudo; saúde é poder trabalhar; saúde é ter disposição; é levantar disposta, trabaIhar... (Quadro 1)

Dentre as subcategorias do conceito de saúde ligado à atividade física, pudemos identificar que estas atividades estavam ligadas ao trabalho, à independência, ao estado de ânimo, bem como às atividades de auto-cuidado e manutenção da vida.

A percepção de saúde como ligada ao estado de ânimo, tanto para o trabalho como para a vida, foi a subcategoria mais mencionada entre as mulheres. No entanto, a atividade física relacionada ao auto-cuidado e manutenção da vida, ainda que pouco referida, foi levantada como segue: saúde é não sentir nada, poder andar, trabalhar e comer; ... é não ter dor $e$ alimentar bem.
Quadro 1 - Categoria: Saúde ligada à atividade física

\begin{tabular}{|c|c|}
\hline \multicolumn{2}{|c|}{$\begin{array}{l}\text { Sub-categorias: } \\
\text { A- Trabalho } \\
\text { C- Estado de ânimo }\end{array}$} \\
\hline B-C- & $\begin{array}{l}\text { saúde é estar e sentir bem, andando } \\
\text { (32) }\end{array}$ \\
\hline A-B-D- & $\begin{array}{l}\text { saúde é não sentir nada, poder andar, } \\
\text { trabalhar e comer (34) }\end{array}$ \\
\hline A-B-C-D- & $\begin{array}{l}\text { é levantar disposta, trabalhar, não ter } \\
\text { dor e alimentar bem (36) }\end{array}$ \\
\hline A-B- & é poder trabalhar, sair (39) \\
\hline A-C- & $\begin{array}{l}\text { saúde é melhor, pode trabalhar, traz } \\
\text { alegria (41) }\end{array}$ \\
\hline C- & ter energia, vitalidade e inteligência (8) \\
\hline A- & com saúde pode trabalhar (42) \\
\hline C- & $\begin{array}{l}\text { saúde é ter mais disposição, } \\
\text { paciência (28) }\end{array}$ \\
\hline A- & $\begin{array}{l}\text { saúde é coisa boa, faz as coisas tudo } \\
\text { certinho (26) }\end{array}$ \\
\hline A-C- & ter coragem de fazer tudo (2) \\
\hline B-C- & $\begin{array}{l}\text { poder ajudar, ter disposição para } \\
\text { tudo(19) }\end{array}$ \\
\hline C- & ter disposição (1) (7) (14) (17) (27) \\
\hline C- & ter ânimo (11) (17) \\
\hline B- & não depender dos outros (6) \\
\hline
\end{tabular}

\section{* Os números representam os sujeitos que ex-} pressaram tais falas.

A referência pelas mulheres de que saúde significa dar um sentido para a vida, como disseram, $\dot{e}$ estar feliz; é ter alegrias; é uma forma de ter mais vida, alimetar-se bem, saber-se cuidar bem, revela que elas entendem saúde como uma questão social que vai além do biológico, da ausência de doença (Quadro 2).

É interessante observar que uma entrevistada simbolizou saúde como algo que é intrínseco ao ser humano - saúde é energia, vitalidade e inteligência que as pessoas têm naturalmente. Uma outra tenta demonstrar que a questão da saúde está vinculada à resolução de problemas de toda ordem: saúde é ter descanso na vida. 
Quadro 2 - Categoria: Saúde como dando sentido para a vida.

- tem disposição para tudo (1) (7)

- ter coragem para fazer tudo (2) (7) (19) (36)

- é bom demais (3)

- é ser feliz (4)

- é maravilhoso (5)

- é energia, vitalidade e inteligência que as pessoas têm naturalmente (8)

- é uma forma de ter mais vida, alimentar bem, saber se cuidar bem (9)

- é coisa boa, é sentir bem (10) (30) (35)

- é sentir bem, sem dor, ter disposição (14)

- vida boa, normal (16)

- é importante, é não sentir nada, alegria, disposição e ânimo (17)

- estar feliz, não sentir nada (18)

- saúde é alegria, é bom demais (31) (33)

- é estar bem, andando (32)

- saúde é melhor que doença, pode trabalhar, traz alegria (41)

- é ter paciência (28)

- saúde é o lado bom (23)

- saúde é mais melhor (25)

- é não sentir nada, ânimo e coragem (11)

- ter descanso na vida (12)

- pessoa que tem saúde é quem tem alegria, pode comprar um brinco novo, uma roupa nova, comer fora. Pobre nunca pode fazer isso (24)

* Os números representam os sujeitos que expressaram tais falas.

Por outro lado, outras mulheres dicotomizam a experiência humana, ao referirem que saúde é o lado bom da vida. A busca de equilíbrio foram também imagens verbalizadas por algumas mulheres como: saúde é ter descanso na vida; é não ter nada. A seguintes expressão: pessoa que tem saúde é que tem alegria, pode comprar um brinco novo, uma roupa nova, comer fora. Pobre nunca pode fazer isso, denota que para essa mulher a questão saúde está forte- mente relacionada à condição sócio-econômica.

XAVIER, ÁVILA e CORREA(7) ao definirem que saúde é estar bem no mundo, lembram que isso se refere não somente à condição corporal, mas também à situação das mulheres em outros campos. Através da verbalização das mulheres, verifica-se que essa perspectiva permite incorporar as ações que buscam a saúde em outros campos: saúde é alegria... ; é estar feliz; é uma forma de ter mais vida, alimentar bem, saber se cuidar bem; é vida boa, normal.

Lembram ainda XAVIER, ÁVILA E CORREA(7) que, se por uma lado, essa abordagem conflitua com a segmentação do sujeito presente na conduta médica, por outro lado, tem inúmeros pontos de convergência com a conceituação de assistência integral, que hoje circula entre os profissionais de saúde que assistem à mulher.

Outra temática possível de identificação, foi o conceito de saúde ligado à ausência de doença, ou seja, um imaginário relacionado à condição biológica e fisiológica. A ausência de dor, enquanto conceito de saúde, é expresso nas seguintes falas: saúde é não sentir nada; ... é não ter dor. Esta expressão foi constante entre as mulheres. Contudo, a fala de muitas mulheres exterioriza a percepção de que cabe ao sujeito também a responsabilidade pela sua saúde como segue: saúde é diferente de doença, pois tratando evita a doença, se tem doença é porque foi descuido (Quadro 3). Estas considerações vêm ao encontro das referências de Pompidou in BUENO e CHIERE$\mathrm{GATO}^{(3)}$, quando afirma que a educação à saúde está ligada fundamentalmente, às responsabilidades do ser humano, no sentido de compreender o valor daquilo que se aprende, e de colocar em prática na vida, aquilo que assimilou, visando a promoção e restauração da saúde.

Uma questão que nos pareceu alarmante, especialmente por ser uma amostra de mulheres jovens, foi a grande porcentagem de mulheres $-54,7 \%$ (23) que se identificaram como doentes ao serem indagadas como elas percebiam, naquele momento, sua condição de saúde. 
Quadro 3 - Categoria: Saúde como ausência de doença

- não sentir nada (12) (15) (21) (29)

- não sentir nada, não ter dor (3)

- é importante, é não sentir nada, alegria, disposição e ânimo (17)

- estar feliz, não sentir nada, poder trabalhar, andar e comer (34)

- saúde é não ter preocupação (38)

- não sentir nada, ânimo e coragem (11)

- é sentir bem, sem dor, ter disposição (14)

- é uma forma de ter mais vida, alimentar bem, saber se cuidar bem (9)

- saúde é diferente de doença, pois tratando evita doença, se tem doenca é porque foi descuido (37)

* Os números representam os sujeitos que expressaram tais falas.

Interessante foi observar nas falas dessas mulheres a tristeza, a dor, o desânimo, desconf orto, preocupação e a possibilidade de dependência, especialmente a física, como não poder trabalhar, sair e ficar na cama, como as principais justificativas alegadas para o seu estado de saúde. (Anexo 2)

Embora estas mulheres expressassem a idéia de que saúde para elas inclui valores e qualidade de vida, daquelas que se situaram como doentes, quando ques- tionadas sobre o que têm feito, muitas deixaram transparecer o descrédito no sistema de saúde, expresso nas seguintes falas: não faço nada; vou no médico mas não adianta...; faço prece; tomo água doce. Por outro lado, a realidade sócio-econômica, aparece como importante barreira para a mudança de situação de saúde como algumas disseram: não tomo a medicação prescrita pelo médico porque não tenho condição de comprar, e, vou no médico mas não adianta pois tenho vontade de comprar as coisas e não posso.

\section{CONSIDERAÇÕES FINAIS}

Os achados deste trabalho, os quais representam a percepção que as mulheres têm sobre saúde, são de fundamental importância para a área de Saúde da Mulher, pois fornecem subsídios para a prestação de assistência orientada para a saúde. E reforçam que o envolvimento coordenado de uma equipe multiprofissional é condição básica para essa assistência, pois nenhum profissional será capaz de encontrar as necessidades de saúde em todas as áreas. Conforme reforça $\mathrm{CHOI}^{(4)}$, o domínio do processo saúde/doença, a interação e influência de cada um dos profíssionais deve ser eqüitativamente representados. Diferentes perspectivas oferecem visões únicas de como as mulheres podem ser compreendidas e assistidas mais completamente, como também poderá facilitar a própria compreensão da mulher sobre questões de sua saúde e família.

\section{REFERÊNCIAS BIBLIOGRÁFICAS}

1. BORGES, S.M.N. Propostas para uma relação: profissionais de sáude e mulheres. Cadernos de Saúde Pública. FIOCRUZ, v. 7, p.284-9, 1991.

2. BRITO, J. C. \& D. ACRI, V. Referencial de análise para o estudo da relação trabalho, mulher e saúde. Cadernos de Saúde Pública, v. 7, n. 2, p. 201-14, 1991.

3. BUENO, S.M.V. e CHIEREGATO, E. Prevenção da AIDS e o Processo de Comunicação na Orientação Inf antil. $3^{\circ}$ SIBRACEn, EERP-USP, ANAIS... Ribeirão Preto, maio, 1992, p. 690-704.

4. CHOI, M.W. Preamble to a new paradigm for women's health care. Image:The Journal of Nursing Scholarship, v. 17, n. 1, p. 14-6, 1985.
5. MAMEDE, M.V. Saúde da Mulher: visão feminista. FEMINA, v. 17, n. 11, p. 904-6, 1989.

6. OMS - New approaches to health education in primary health care. Technical Report Series. n. 690, 1983

7. XAVIER, D., ÁVILA, M. B. \& CORREA, A. Questões feministas para a ordem médica: o feminismo e o conceito de saúde integral. In: LABRA, E., Mulher, saúde e sociedade no Brasil. Petrópolis: Vozes, p. 203-22, 1989.

8. WEBSTER, D. \& LIPETZ, M. Changing definitions; chances times. Nursing Clinics of North America, v. 21, n. 1, p. 87-97, 1986. 
Anexo 1 - Sianificado de Saúde

- pessoa sadia tem disposição para tudo (1)

- tem coragem de fazer tudo (2)

- é bom demais (3)

- é ser feliz (4)

- é maravilhoso (5)

- não depende dos outros (6)

- tem disposição (7)

- é energia, vitalidade e inteligência que as pessoas tem naturalmente (8)

- é uma forma de ter mais vida, alimentar bem, saber se cuidar bem para não fica doente (9)

- é coisa boa, é sentir bem (10)

- é não sentir nada, ânimo e coragem (11)

- ter descanso na vida (12)

- não sentir nada, não ter dor (13)

- é sentir bem, sem dor, ter disposição (14)

- é não sentir nada, despreocupada (15)

- vida boa, normal (16)

- é importante, é não sentir nada, alegria, disposição e ânimo (17)

- estar feliz, não sentir nada (18)

- ajuda e tem disposição para tudo (19)

- pessoa não sente nada (21)

- saúde é o lado bom (23)

- pessoa que tem saúde é quem tem alegria, pode comprar um brinco novo, uma roupa nova, comer fora. Pobre nunca pode fazer isso (24)

- saúde é mais melhor (25)

- saúde é coisa boa, faz as coisas tudo certinho (26)

- estando doente não tem saúde, não tem disposição (27)

- é ter paciência (28)

- saúde não tem nada (29)

- saúde é coisa boa (30)

- saúde é alegria, é bom demais (31)

- é estar bem, andando (32)

- saúde é alegria (33)

- estar feliz, não sentir nada, poder trabalhar, andar e comer (34)

- saúde é coisa boa (35)

- é levantar disposta, trabalhou, não ter dor, alimentar bem (36)

- saúde é diferente de doença, pois tratando evita doença, se tem doença é porque foi descuido (37)

- saúde é não ter preocupação (38)

- saúde pode trabalhar, sair (39)
- saúde é bem melhor que doença (40)

- saúde é melhor que doença, pode trabalhar, traz alegria (41)

- com saúde pode trabalhar (42)

Anexo 2 - Justificativa das mulheres que se consideram doentes.

- não tenho disposição; dor nas pemas e na cabeça (1)

- estou resfriada (2)

- tenho dor (4)

- por causa dos problemas que tenho (5)

- porque tenho ferida no útero e infecção (6)

- preocupada com "amigo" que bebe (12)

- dor na barriga (grávida) (13)

- unheiro (17)

- gastrite (20)

- problema da vagina, tenho medo de doença grave (23)

- vivo mais doente, não tenho alegria, vivo com dor (24)

- sou doente porque se estivesse legal, estava mais animada (25)

- está sangrando (31)

- não durmo, tenho fraqueza (32)

- estou muito gorda (34)

- acho que tenho Aids (35)

- estou cansada (36)

- acho que tenho Aids (37)

- faz um ano que tenho gripe (38)

- quase não dei conta de chegar aqui. Tenho problema de estômago e gastrite (39)

- dói muito por baixo, por causa da operação (40)

- tenho glaucoma e desvio de coluna. Tem feito tratamento no H.C.; o médico manda tomar remédio só que não compro (41)

- tenho corrimento diário, tem cheiro ruim e é claro (42) 